ORIGINAL RESEARCH PAPER

\title{
CONCENTRATING ROSMARINIC ACID FROM ORTHOSIPHON ARISTATUS EXTRACT FOR HIGH ANTIOXIDATIVE CANDIES
}

\author{
JIN RU LIM ${ }^{1}$, LEE SUAN CHUA ${ }^{1,2 *}$ \\ ${ }^{1}$ Institute of Bioproduct Development, Universiti Teknologi Malaysia, 81310 UTM Skudai, Johor \\ Bahru, Johor, Malaysia. \\ ${ }^{2}$ Department of Bioprocess and Polymer Engineering, School of Chemical and Energy \\ Engineering, Faculty of Engineering, Universiti Teknologi Malaysia, 81310 UTM Skudai, Johor \\ Bahru, Johor, Malaysia. \\ *corresponding author: chualeesuan@utm.my \\ Received on 23 March 2021 \\ Revised on 5 May 2021
}

\begin{abstract}
Extraction and fractionation were carried out to concentrate the rosmarinic acid from Orthosiphon aristatus in order to increase the value of herbal candy formulated using polyphenolic rich extract. The herb was extracted and fractionated in column chromatography, and then analyzed by LC-MS/MS. The collected plant fractions with similar chromatographic profiles were combined and determined for antioxidant capacities expressed in radical scavenging activity. The results showed that the antioxidant capacity was in good agreement with the concentration of rosmarinic acid in the combined fractions. The combined fraction II showed the highest rosmarinic acid content, $3.8 \% \mathrm{w} / \mathrm{w}$ and the highest antioxidant capacity (IC50=14.922 ppm). The incorporation of rosmarinic acid rich extract into candy formulation did not statistically affect the antioxidant capacity. Hence, the rosmarinic acid rich extract could be another choice of ingredient to enhance the beneficial property of candies. Candy is another form of carrier to deliver herbal ingredient for health promotion.
\end{abstract}

Keywords: Orthosiphon aristatus, rosmarinic acid, candy, column chromatography, radical scavenging

\section{Introduction}

Malaysia is one of the well-known countries in South East Asia actively using traditional herbal medicine to this day. Recently, the application of herbs and herbal products for overall well-being are increasingly accepted by public. Orthosiphon aristatus which is locally known as 'Misai Kucing' (Cat's whisker) belongs to the Lamiaceae family and commonly consumed as herbal tea. It is a medicinal plant that is native in temperate and tropical areas, such as: India, Malaysia, Indonesia, Thailand, the Pacific and some parts of tropical Australia (Movahedi et al., 2014).

https://doi.org/10.35219/foodtechnology.2021.1.08 
$O$. aristatus is traditionally used to treat diuresis, rheumatism, diabetes, urinary lithiasis, oedema, hypertension, renal calculus, gall-stone and hepatitis (Amzad Hossain and Mizanur Rahman, 2011).

Previous scientific studies demonstrated that $O$. aristatus extract contained phenolic and polyphenols, such as rosmarinic acid, eupatorine, sinensetin, 3'-hydroxy5,6,7,4'-tetramethoxyflavone and salvigenin (Amzad Hossain and Mizanur Rahman, 2011; Saidan et al., 2015). Rosmarinic acid was the major phytochemical which is likely to be the marker compound of the plant (Akowuah et al., 2004; Pariyani et al., 2015; Shafaei et al., 2016). The rosmarinic acid is a phenylpropanoid, which demonstrates high medical value due to its pharmacological significance, particularly on antioxidant (Tepe et al., 2007; Erkan et al., 2008), antimicrobial (Matejczyk et al., 2018; Benedec et al., 2015), anti-inflammatory (Rocha et al., 2015) activities and hepatic protection properties (El-Lakkany et al., 2017), as well as in inhibiting angiotensin I-converting enzyme (Shafaei et al., 2016). Dixon et al. (2005) revealed that therapeutic benefits of medicinal plants are mainly attributed to their antioxidant properties.

A plant extract is a highly complex mixture of phytochemicals with different characteristics. Column chromatography could concentrate bioactive phytochemical(s), instead of crude extract for the formulation and development of value added products (Sasidharan et al., 2011). Column chromatography was proven to be a reliable separation technique to fractionate the crude extract of $O$. stamineus (Chua and Lau, 2017). The presence of bioactive rich plant extract would increase the biological activity of formulated products.

Since natural product samples have a very complicated phytochemical composition, hyphenated techniques, like the liquid chromatography tandem mass spectrometry (LC-MS/MS), represent a reliable technique for high throughput phytochemical screening. The system integrates a powerful separation liquid chromatography with an excellent identification instrument. This also explains the wide application of LCMS/MS in polyherbal formulations (Lau et al., 2003; Hossain et al., 2010). Some researchers used the chemometric approach to analyze large multivariate data for data mining (Shi et al., 2017). The principal component analysis and hierarchical cluster analysis are commonly used by researchers to visualize and identify key compounds in a group of samples (Sim et al., 2003).

Therefore, the present study was conducted to fractionate the crude extract of $O$. aristatus in order to concentrate rosmarinc acid using column chromatography. The antioxidant capacity of the fractionated samples was further analyzed for their antioxidant capacity, in terms of radical scavenging activity. The stability of the rosmarinic acid was also proven even after incorporating into candy formulation.

\section{Materials and methods}

\section{Reagents and chemicals}

Analytical grade of ethanol (96\%) was purchased from QReC (Asia) Sdn. Bhd. (Rawang, Malaysia). Both analytical and HPLC grades of methanol were purchased 
from Fisher Scientific (Loughborough, UK). Acid washed sea sand and glass wool were purchased from R\&M Chemicals (Semenyih, Malaysia). Silica 60 (0.063-0.2 $\mathrm{mm}$ ) was purchased from Macherey-Nagel GmbH (Duren, Germany). DPPH (2.2Diphenyl-1-picrylhydrazyl and rosmarinic acid $(\geq 98 \%)$ were purchased from SigmaAldrich Corp. (St. Louis, USA).

\section{Reflux extraction of Orthosiphon aristatus}

The dried and ground $O$. aristatus $(5.0 \mathrm{~g})$ was extracted by water $(250 \mathrm{~mL})$ using a reflux system in a stirring heating mantle (MTOPS ${ }^{\circledR}$ MS-ES303, South Korea) for one hour. The dried and ground sample was immersed in water for one hour before extraction. The extract solution was filtered and concentrated by a rotary evaporator, and further dried completely in an oven at $50^{\circ} \mathrm{C}$. The yield of extract was recorded and kept in a refrigerator for further analysis.

\section{Fractionation of crude extract}

A silica 60 packed column $(50 \mathrm{~g}, 3 \times 16 \mathrm{~cm})$ was prepared and used to fractionate the crude extract of $O$. aristatus using the solvent systems of $96 \%$ ethanol, $50 \%$ ethanol $+50 \%$ water, $100 \%$ water and acidified water with acetic acid $(\mathrm{pH} 2.0)$ in sequence. The crude extract $(0.5 \mathrm{~g})$ was reconstituted in water and ethanol $(5 \mathrm{~mL})$, and loaded on top of the packed column for fractionation. The first solvent system which was $96 \%$ ethanol was slowly added and eluted through the packed column concurrently at a constant flow rate $(5 \mathrm{~mL} / \mathrm{min})$. The solvent system was used as a carrier to elute compounds with similar polarity in the crude extract and collected in test tubes. Thirteen tubes with $5 \mathrm{~mL}$ of sample solution were collected as plant fractions for each solvent system in increasing polarity. The fractions were dried in an oven at $50^{\circ} \mathrm{C}$, and the weight of each fraction was recorded.

\section{High throughput phytochemical screening}

A high throughput phytochemical screening was carried out by a hyphenated system of liquid chromatography tandem mass spectrometer (LC-MS/MS). The liquid chromatography was from Dionex Corporation (Ultimate 3000; Sunnyvale, CA) integrated with a diode array detector and a C18 reversed phase XSelect HSS T3 column $(2.1 \times 100 \mathrm{~mm}, 2.5 \mu \mathrm{m})$. The mass spectrometer was a quadrupole and timeof-flight (QTOF) system from AB SCIEX (QSTAR Elite; Foster City, CA). All samples were screened by LC-MS/MS. Samples were filtered by nylon membrane filter $(0.2 \mu \mathrm{m})$ prior to injection $(5 \mu \mathrm{L})$. Solvent A (water with $0.1 \%$ formic acid) and solvent B (acetonitrile) were used as the binary mobile phase at the flow rate of $150 \mu \mathrm{L} / \mathrm{min}$. The gradient was programmed as: 0-10 min, $90 \% \mathrm{~A} ; 10-20 \mathrm{~min}, 90-$ $15 \%$ A; $20-25 \min , 15 \%$ A; $25-26$ min, $15-90 \%$ A; $26-30$ min, $90 \%$ A. The mass range of screening was set from $\mathrm{m} / \mathrm{z} 100-1000$. The voltages of ion spray were set at $4500 \mathrm{~V}$ and $5500 \mathrm{~V}$ for negative and positive ion modes, respectively. The potentials of declustering and focusing were set at $40 \mathrm{~V}$ and $250 \mathrm{~V}$, respectively. Nitrogen was used as the nebulizing (40 psi) and curtain gas (20 psi).

\section{Determination of rosmarinic acid}

The chromatograms of samples in each tube were analysed at $254 \mathrm{~nm}$. Samples with similar chromatographic profiles were combined and named as Fraction I to VII. The 
concentrations of rosmarinic acid in the combined fractions were determined from a calibration curve. The calibration curve was constructed using a serial standard solution of rosmarinic acid ranged from 20-100 ppm.

\section{Preparation of herbal candies}

The ingredients for candy preparation included table sugar (100 g), light corn syrup $(40 \mathrm{~g})$ and water $(40 \mathrm{~g})$. The ingredients were mixed and heated slowly until the solution was boiled. The syrup solution was continuously stirred at $120{ }^{\circ} \mathrm{C}$. Then, the combined fractions were added and well mixed in the syrup solution before transferred into a mould. The concentration of the combined fractions was ranged from 40-200 ppm in the syrup solution. The herbal syrup was cooled at room temperature for overnight. The volume of each candy was $3 \mathrm{~mL}$.

\section{DPPH Radical Scavenging activity}

DPPH solution $(0.1 \mathrm{mM})$ was freshly prepared by dissolving $4 \mathrm{mg}$ DPPH in $100 \mathrm{~mL}$ methanol. Three candies $(\sim 10 \mathrm{~g})$ were melted in $9 \mathrm{~mL}$ hot water. A $1 \mathrm{~mL}$ sample solution was added into the DPPH solution $(1 \mathrm{~mL})$ and incubated at $25{ }^{\circ} \mathrm{C}$ for $30 \mathrm{~min}$ in the dark place. The absorbance of the solution was measured at $517 \mathrm{~nm}$ using a spectrophotometer (UV-1800, Shimadzu, Japan). The DPPH radical scavenging activity of the combined fractions I to VII was calculated using Equation 1.

$$
\% \text { Inhibition }=\frac{A b-A a}{A b} 100
$$

$\mathrm{Ab}$ is the absorption of blank sample and Aa is the absorption of fractions. The DPPH radical scavenging activity is expressed as $\mathrm{IC}_{50}$ which is the required concentration of sample to exhibit $50 \%$ inhibition against free radicals.

\section{Statistical Analysis}

A multivariate data analysis technique based on principal components was used to analyse the large datasets of mass spectrometric data. Principal component analysis (PCA) with Pareto scaling was used to analyse highly complex mass spectra under unsupervised condition (MarkerView 1.2.1, Foster City, CA). The minimum spectral peak width and mass tolerance were set at 0.05 and $0.10 \mathrm{Da}$, respectively. The retention time tolerance was $0.5 \mathrm{~min}$ and the maximum number of peaks was 10,000 .

\section{Results and discussion}

\section{Column chromatography of crude extract}

The phytochemicals in herbal plants are usually extracted and prepared in the form of decoction. In the present study, the extract of $O$. aristatus was further dried into crude extract powder for storage and product formulation. The water extraction using reflux system was found to produce higher yield (22\%) than alcoholic extract (3-14 $\%$ ) in previous studies (Chua and Lau, 2017). The dried water extract was dark and sticky because of hygroscopic nature of polysaccharides. Even though higher yield, the phytochemicals with chromophore property were less than those extracted by 
ethanolic solvent, especially after compounds detected at the retention time after 17 min. The crude extract was then fractionated into several fractions using column chromatography with increasing polarity of eluent. The color and dry weight of individual fractions collected by the 4 solvent systems is presented in Figure 1 .

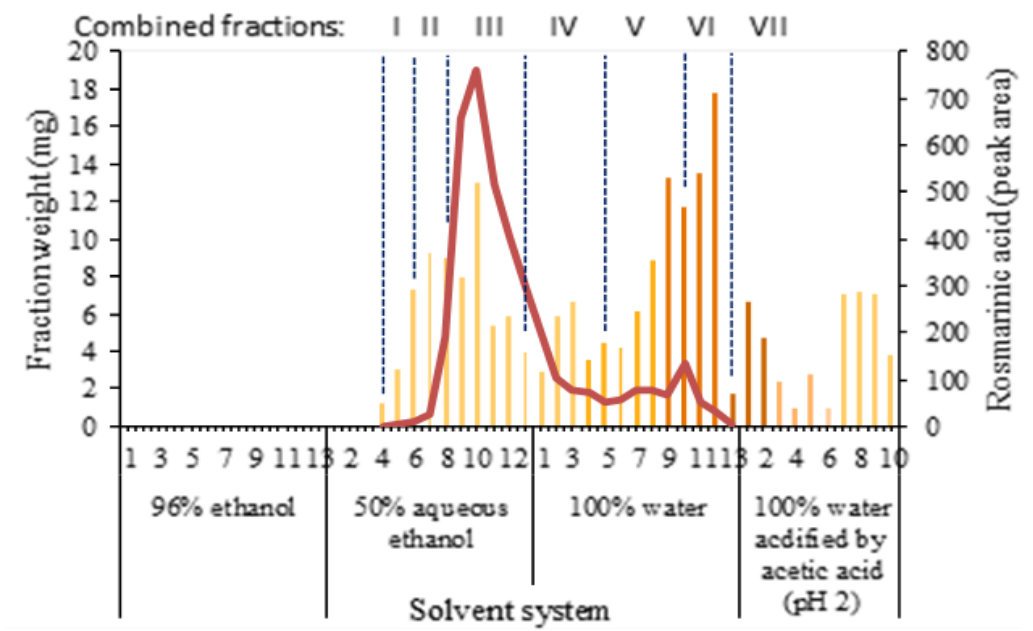

Figure 1. Weight of fractions collected from column chromatography using 4 solvents system in increasing polarity.

The color of the fractions was changed from yellowish, to brown and light brown. The dried weight of fractions collected by each solvent system; $0 \mathrm{mg}$ (100\% ethanol), $66.0 \mathrm{mg}$ (50\% ethanol 50\% water), $100.6 \mathrm{mg}$ (100\% water) and $43.6 \mathrm{mg}$ (acidified water at $\mathrm{pH} 2.0$ ). It was found that only $42 \%$ of crude extract could be recovered from column chromatography. There were 58\% of crude extract still remaining in the packed column as residue. The remaining compounds strongly bound to the surface of silica. The principle of work in column chromatography is depended upon the adsorption strength between molecules in mobile phase and the stationary phase of column. This observation shows that the residue could be highly polar compounds like polysaccharides. The results of fractionation by column chromatography also showed that only $13.2 \%$ of crude extract could be recovered by intermediate polarity of ethanolic solvent. The solvent system of $100 \%$ water could achieve the highest recovery, $20.1 \%$ since water was used as solvent for reflux extraction. The addition of acetic acid may increase the number of protons in the eluent to weaken the interaction of molecules on the surface of silica. This would accelerate the elution of compounds out from the column. The rest of compounds in the crude extract belonged to highly polar substances (residue).

\section{Pattern recognition of mass spectrometric data}

The mass spectrometric data of samples were analyzed using principal component analysis statistically. The score and loading plots of both negative and positive ion modes are presented in Figure 2. 

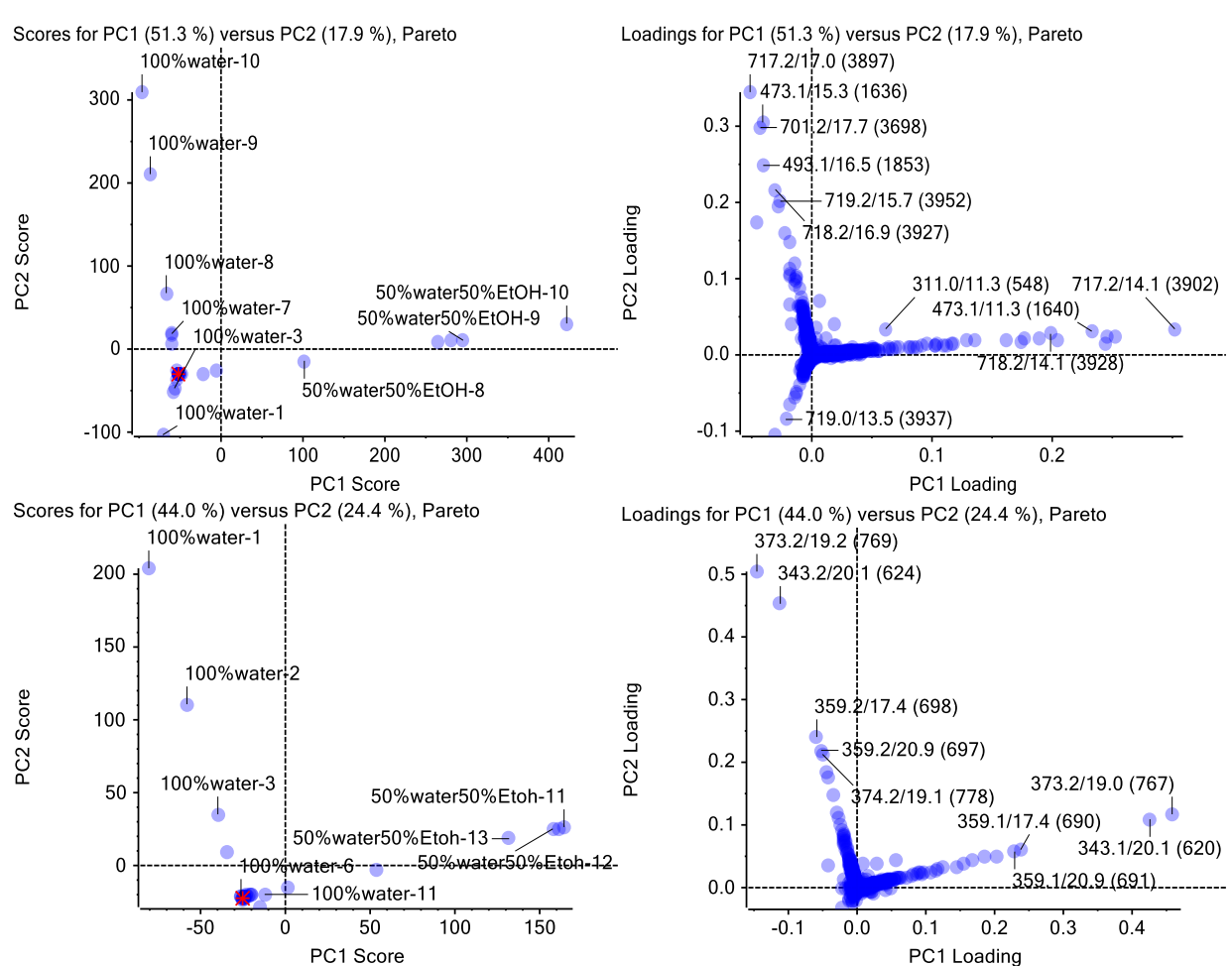

Figure 2. Score and loading plots of principle component analysis for phytochemicals detected at the negative ( $a$ and $b$ ) and positive (c and d) ion modes.

An opposite trend can be seen from the score plots of negative and positive ion modes. The first two principal components accounted for $69.2 \%$ of total variance for negative ion mode, whereas $68.4 \%$ of total variance for positive ion mode. Phytochemicals in the fractions collected from the solvent system of $50 \%$ ethanol and $50 \%$ water appeared to contribute to the largest variance as shown in the first principal component. The phytochemicals in the green circles are located far away from the central point of the loading plots. They were likely to be the major phytochemicals differentiating the fractions. The fragments of the compounds were matched to the data published in literature. The results found that 5 major compounds such as rosmarinic acid (m/z 359), xylosyglucosyl caffeic acid (m/z 473), deoxysalvianolic acid B (m/z 701), salvianolic acid (m/z 717) and dirosmarinic acid $(\mathrm{m} / \mathrm{z} 719)$ were identified in the negative ion mode. They are caffeic acid derivatives which are preferably ionized by losing a proton. While, 4 compounds such as tetramethoxyflavone (m/z 343), eupatorin (m/z 345), 5-hydroxy-6,7,3',4'tetramethoxyflavone $(\mathrm{m} / \mathrm{z} 359)$ and sinensetin $(\mathrm{m} / \mathrm{z} 373)$ were detected as the major phytochemicals in the positive ion mode. They are polymethoxyflavones which are prone to accept a proton during ionization (Cho et al., 2014). Table 1 shows the fragment ions of the major compounds in both negative and positive ion modes. 
Table 1. The detected major phytochemicals which are tentatively identified from their mass fragmentation at the negative and positive ion modes.

\begin{tabular}{|c|c|c|c|}
\hline \multicolumn{4}{|c|}{ Negative ion } \\
\hline $\begin{array}{l}\text { Retention } \\
\text { time (min) }\end{array}$ & $\begin{array}{c}\text { Mass per } \\
\text { charge }(\mathbf{m} / \mathbf{z})\end{array}$ & Tentative compounds & Fragment ions \\
\hline 12.0 & 473 & $\begin{array}{l}\text { Xylosyglucosyl caffeic } \\
\text { acid }\end{array}$ & $\begin{array}{l}473 / 219(-254) / 179(-294) / \\
149 / 135\end{array}$ \\
\hline 13.0 & 359 & Rosmarinic acid & $359 / 197 / 179 / 161$ \\
\hline 13.5 & 719 & Rosmarinic acid dimer & $\begin{array}{l}\text { 719/359(-360)/297/197/ } \\
179 / 161 / 133\end{array}$ \\
\hline 14.0 & 717 & Salvianolic acid B & $\begin{array}{l}\text { 717/519(- } \\
198) / 339(378) / 321 / 295 / 27 \\
7 / 197 / 185\end{array}$ \\
\hline 15.0 & 701 & Deoxysalvianolic acid B & $\begin{array}{l}701 / 339(-362) / 321 / 295 / \\
279 / 185\end{array}$ \\
\hline \multicolumn{4}{|c|}{ Positive ion } \\
\hline 19.0 & 373 & Sinensetin & \\
\hline 19.4 & 345 & $\begin{array}{l}\text { Eupatorin (3',5-dihydroxy- } \\
\text { 4',6,7-trimethoxyflavone) }\end{array}$ & $\begin{array}{l}345 / 330 / 312 / 284 / 269 / 185 \\
/ 147 / 136\end{array}$ \\
\hline 20.2 & 343 & Tetramethoxyflavone & $\begin{array}{l}343 / 327 / 313 / 299 / 285 / 254 \\
/ 238 / 155\end{array}$ \\
\hline 21.0 & 359 & $\begin{array}{l}\text { 5-hydroxy-6,7,3',4'- } \\
\text { tetramethoxyflavone }\end{array}$ & $\begin{array}{l}359 / 343 / 329 / 315 / 298 / 283 \\
/ 255 / 227 /\end{array}$ \\
\hline
\end{tabular}

\section{Plant fractions rich in polyphenolic compounds}

The fractions with similar chromatographic profiles were combined and further analysed for their antioxidant capacities in candy formulation. A total of 7 combined fractions (I-VII) was formed from the crude extract. The chromatograms of the combined fractions are presented in Figure 3. The chromatograms of combined fractions VI and VII are hardly to see any significant peak at $254 \mathrm{~nm}$. The rosmarinic acid was detected at $13 \mathrm{~min}$ and its peak also presented at the highest concentration in the combined fractions II and III. The concentration of rosmarinic acid in each combined fraction is presented in Figure 4. The figure shows a significant increment of the rosmarinic acid content after column chromatography. The combined fraction II and III show the highest rosmarinic acid content which were increased from $0.05 \%$ in crude extract to $3.8 \%$ and $2.3 \%$ in the combined fraction II and III, respectively. Rosmarinic acid was prone to be eluted by aqueous ethanol effectively. As seen in Figure 4, the eluent of acidified water at $\mathrm{pH} 2.0$ could assist in eluting the remaining rosmarinic acid bound to the surface of silica. The competitive interaction between mobile phase and silica based stationary phase could be illustrated by the elution profile of rosmarinic acid. 


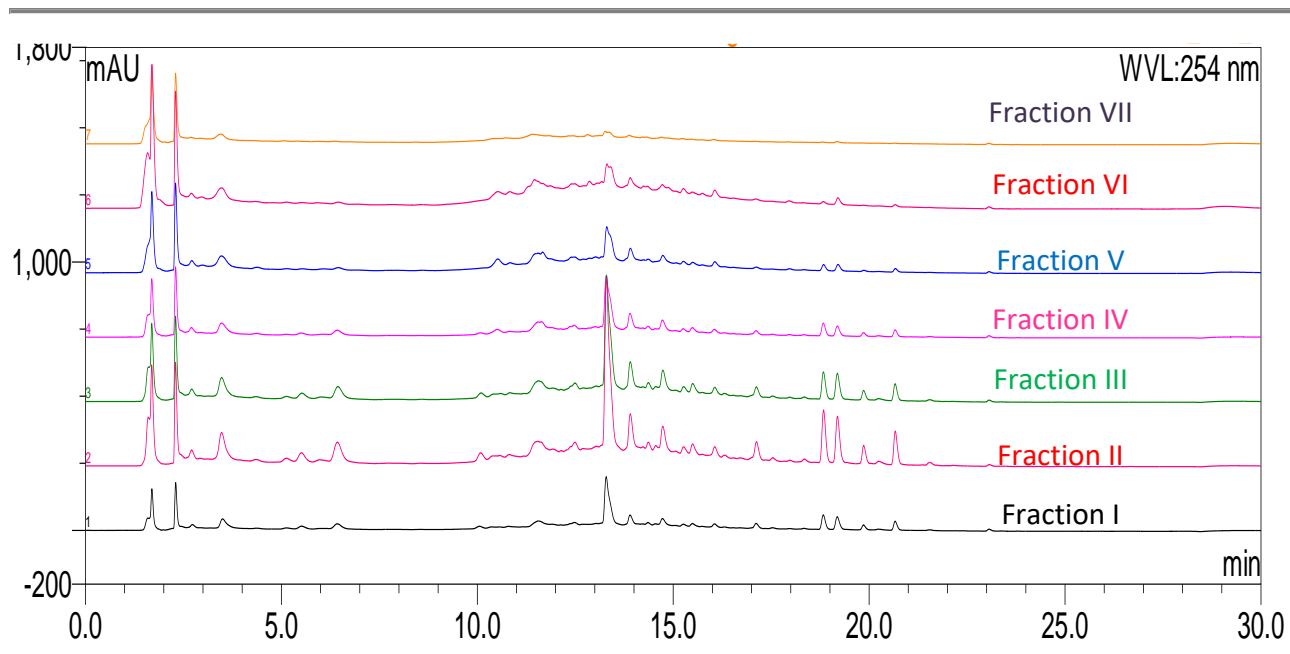

Figure 3. Chromatograms of the combined fractions from column chromatography using Orthosiphon aristatus extract.

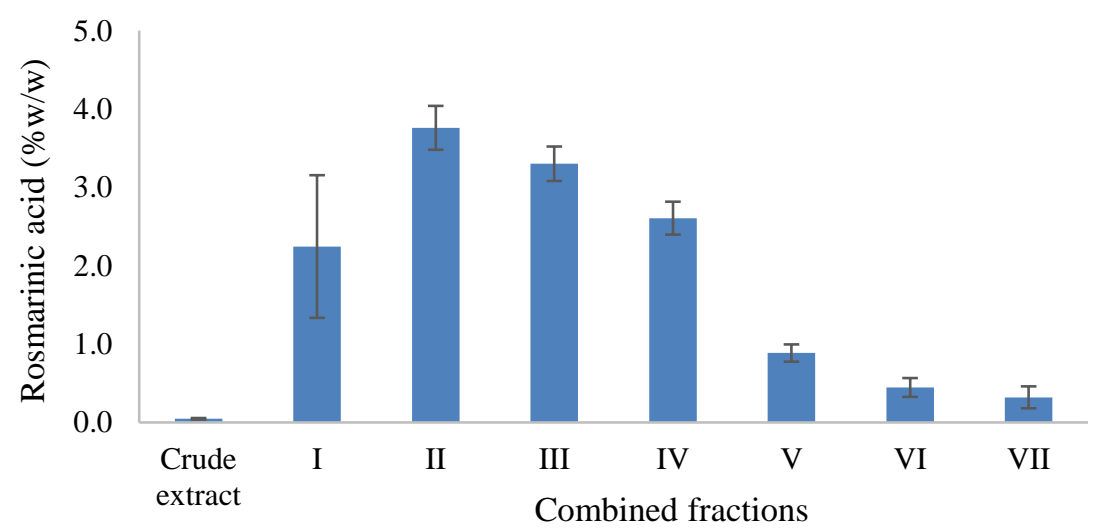

Figure 4. Rosmarinic acid content in the combined fraction I - VII.

\section{Free radical scavenging activity of combined fractions}

In the assay of radical scavenging, the purple free radicals, $\mathrm{DPPH}^{\bullet}$ would be reduced to a yellowish solution which is a stable and complex end product after reacted with antioxidant compounds (Kedare and Singh, 2011). The capability of combined fractions in reducing free radicals was expressed in IC50, which explains the required concentration of sample to scavenge 50\% free radicals. Hence, the lower the $\mathrm{IC}_{50}$ value describes the higher antioxidant activity of sample. Figure 5 shows the free radical scavenging activity of combined fractions before and after formulated into candy solution. Obviously, the combined fraction VII shows the lowest antioxidant capacity. The antioxidant capacity of the combined fractions was found to be in rosmarinic acid dependent manner. In other words, fractions with higher rosmarinic acid would exhibit higher antioxidant capacity (Benedec et al., 2015). 
The combined fractions of II and III shows to have lower IC50 with higher antioxidant capacity.

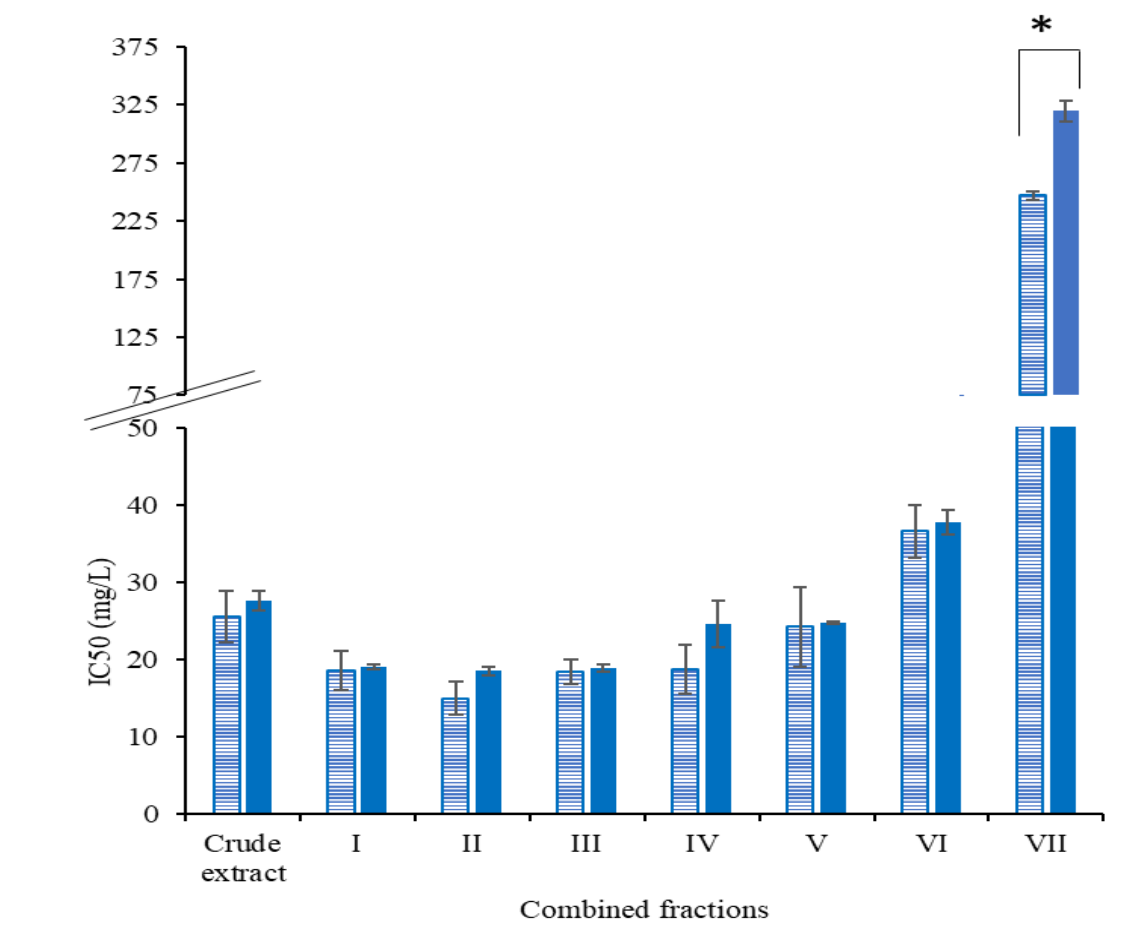

Figure 5. Effective concentration at 50\% inhibition (IC50) against free radicals of DPPH exhibited by samples before (line bar) and after formulated into candies (solid bar).

*indicates the significant difference at $95 \%$ confident level using one-way ANOVA.

Figure 5 also shows to have insignificant difference $(p>0.05)$ between the antioxidant capacity of combined fractions after incorporated into candy formulation. Therefore, the process of candy preparation did not degrade any compounds in the fractions, especially rosmarinic acid. It is interesting because the rosmarinic acid rich fraction could be used as bioactive ingredient in candy formulation. The condensation between the hydroxyl groups of rosmarinic acid and hydroxyl groups of sugar which lead to the formation of glycoside was not significant to reduce the antioxidant capacity of fractions (Shalaby et al., 2016; Nakilcioglu-Tas, 2018).

\section{Conclusions}

This study demonstrated that column chromatography could effectively concentrate the rosmarinic acid from the crude extract of $O$. aristatus. The rosmarinic acid rich fraction could be used to prepare candy with antioxidant property. This value added 
herbal candy is suggested to food manufacturing companies. The rosmarinic acid rich fraction could be another ingredient choice to enhance the value of product.

\section{Acknowledgments}

The works were supported by the research grant of Universiti Teknologi Malaysia (TDR-07G21-06G75) and (HR-08G84).

\section{References}

Akowuah, G.A., Norhayati, I., Zhari, I., Sadikun, A., Khamsah, S.M. 2004. Sinensetin, eupatorin, 3'-hydroxy-5, 6, 7, 4'-tetramethoxyflavone and rosmarinic acid contents and antioxidative effect of Orthosiphon stamineus from Malaysia. Food Chemistry, 87(4), $559-566$.

Amzad Hossain, M., Mizanur Rahman, S.M. 2011. Isolation and characterisation of flavonoids from the leaves of medicinal plant Orthosiphon stamineus. Arabian Journal of Chemistry, 8(2), $218-221$.

Benedec, D., Hanganu, D., Oniga, I., Tiperciuc, B., Olah, N.K., Raita, O., Bischin, C., Silaghi-Dumitrescu, R., Vlase, L. 2015. Assessment of rosmarinic acid content in six Lamiaceae species extracts and their antioxidant and antimicrobial potential. Pakistan Journal of Pharmaceutical Sciences, 28(6), 2297 - 2303.

Cho, H.E., Ahn, S.Y., Kim, S.C., Woo, M.H., Hong, J.T., Moon, D.C. 2014. Determination of flavonoid glycosides, polymethoxyflavones, and coumarins in herbal drugs of citrus and poncirus fruits by high performance liquid chromatography-electrospray ionization/tandem mass spectrometry. Analytical Letters, 47(8), 1299-1323.

Chua, L.S., Lau, C.H. 2017. Reflux extraction and column chromatography for rosmarinic acidrich fraction from Orthosiphon stamineus. Natural Product Journal, 7(1), 2210-3155.

Dixon, R.A., Xie, D.E.Y., Sharma, S.B. 2005. Proanthocyanidins - a final frontier in flavanoid research? New Phytologist, 165(1), 9 -28.

El-Lakkany, N.M., El-Maadwy, W.H., El-Din, S.H., Hammam, O.A., Mohamed, S.H., Ezzat, S.M., Safar, M.M., Saleh, S. 2017. Rosmarinic acid attenuates hepatic fibrogenesis via suppression of hepatic stellate cell activation/proliferation and induction of apoptosis. Asian Pacific Journal of Tropical Medicine, 10(5), 444 - 453.

Erkan, N., Ayranci, G., Ayranci, E. 2008. Antioxidant activities of rosemary (Rosmarinus officinalis L.) extract, blackseed (Nigella sativa L.) essential oil, carnosic acid, rosmarinic acid and sesamol. Food Chemistry, 110(1), $76-82$.

Hossain, M.B., Rai, D.K., Brunton, N.P., Martin-Diana, A.B., Barry-Ryan, C. 2010. Characterization of phenolic composition in Lamiaceae spices by LC-ESI-MS/MS. Journal of Agricultural and Food Chemistry, 58(19), 10576-10581.

Kedare, S.B., Singh, R.P. 2011. Genesis and development of DPPH method of antioxidant assay. Journal of Food Science and Technology, 48(4), 412-422.

Lau, A.J., Holmes, M.J., Woo, S.O., Koh, H.L. 2003. Analysis of adulterants in a traditional herbal medicinal product using liquid chromatography-mass spectrometry-mass spectrometry. Journal of Pharmaceutical and Biomedical Analysis, 31(2), 401 - 406.

Matejczyk, M., Swislocka, R., Golonka, A., Lewandowski, W., Hawrylik, E. 2018. Cytotoxic, genotoxic and antimicrobial activity of caffeic and rosmarinic acids and their 
lithium, sodium and potassium salts as potential anticancer compounds. Advances in Medical Sciences, 63(1), 14 -21.

Movahedi, A., Basir, R., Rahmat, A., Charaffedine, M., Othman, F. 2014. Orthosiphon stamineus: an Asian tea with substantial anticancer properties. Journal of Nutritional Sciences and Dietetics, 1(1), $44-52$.

Nakilcioglu-Tas, E. 2018. The effects of sugar addition and degree of roast on the bioactive compounds and antioxidant activity of Turkish-style coffee brews. Indian Journal of Pharmaceutical Education and Research, 52(3), 456 - 466.

Pariyani, R., Ismail, I.S., Azam, A.A., Abas, F., Shaari, K., Sulaiman, M.S. 2015. Phytochemical screening and acute oral toxicity study of Java tea leaf extracts. BioMed Research International, 2015, 742420.

Rocha, J., Eduardo-Figueira, M., Barateiro, A., Fernandes, A., Brites, D., Bronze, R., Duarte, C.M.M., Serra, A.T., Pinto, R., Freitas, M., Fernandes, E., Silva-Lima, B., Mota-Filipe, H., Sepodes, B. 2015. Anti-inflammatory effect of rosmarinic acid and an extract of Rosmarinus officinalis in rat models of local and systemic inflammation. Basic and Clinical Pharmacology \& Toxicology, 116(5), 398 - 413.

Saidan, N.H., Ridzuan Hamil, M.S., Memon, A.H., Abdelbari, M.M., Hamdan, M.R., Mohd, K.S., Abdul Majid, A.M.S., Ismail, Z. 2015. Selected metabolites profiling of Orthosiphon stamineus Benth leaves extracts combined with chemometrics analysis and correlation with biological activities. BMC Complementary Medicine and Therapies, 15: 350.

Sasidharan, S., Chen, Y., Saravanan, D., Sundram, K.M., Yoga Latha, L. 2011. Extraction, isolation and characterization of bioactive compounds from plants' extracts. African Journal of Traditional, Complementary and Alternative Medicines, 8(1), 1- 10.

Shafaei, A., Sultan Khan, M.S., Aisha, A.F.A., Abdul Majid, A.M.S., Hamdan, M.R., Mordi, M.N., Ismail, Z. 2016. Flavonoids-rich Orthosiphon stamineus extract as new candidate for angiotensin I-converting enzyme inhibition: a molecular docking study. Molecules 21(11), 1500.

Shalaby, E.A., Mahmoud, G.I., Shanab, S.M.M. 2016. Suggested mechanism for the effect of sweeteners on radical scavenging activity of phenolic compounds in black and green tea. Frontiers in Life Science, 9(4), 241 - 251.

Shi, X., Wu, Y., Lv, T., Wang, Y., Fu, Y., Sun, M., Shi, Q., Huo, C., Wang, Q., Gu, Y. 2017. A chemometric-assisted LC-MS/MS method for the simultaneous determination of 17 limonoids from different parts of Xylocarpus granatum fruit. Analytical and Bioanalytical Chemistry, 409, 4669-4679.

Sim, C.O., Ahmad, M.N., Ismail, Z., Othman, A.R., Noor, N.A.M., Zaihidee, E.M. 2003. Chemometric classification of herb - Orthosiphon stamineus according to its geographical origin using virtual chemical sensor based upon fast GC. Sensors, 3(10), 458-471.

Tepe, B., Eminagaoglu, O., Askin Akpulat, H., Aydin, E. 2007. Antioxidant potentials and rosmarinic acid levels of the methanolic extracts of Salvia verticillata (L.) subsp. verticillata and S. verticillata (L.) subsp. amasiaca (Freyn \& Bornm.) Bornm. Food Chemistry, 100(30): $985-989$. 